\title{
THE ROLE OF THE INTERNATIONAL REINSURANCE BROKER
}

\author{
J. S. Greig
}

The title of my paper is "The Role of the International Reinsurance Broker". Some of you may be surprised that Reinsurance Brokers lead a separate existence from Insurance Brokers and indeed many Reinsurance Brokers are offshoots of major Insurance broking houses. However there is a small but distinguished band of Brokers who specialize in Reinsurance, and it is their role, in the context of the risk of earthquake, I propose to examine.

\section{BACKGROUND}

Simply put, the Reinsurance Broker's role is to assist and advise his clients (the Reinsured) with realistic solutions to their Reinsurance needs in the light of his expertise in the business being reinsured and his knowledge of the World market.

At any moment of time in both developing or developed countries there exists a strong potential appetite and capacity for profitable reinsurance business. There also exists a strong potential demand, often from the very same institutional and geographical sources, for cover on risks which for a variety of reasons insurance institutions cannot or do not wish to retain.

The nature of such "surplus risk" varies at one extreme from the reinsurance of small local insurance companies in respect of a modest local enterprise where they wish to accept a share larger than they can retain, to the other extreme of protecting an entire nation in respect of a momentous catastrophic exposure such as is the case here in New Zealand.

The capacity and appetite for the acceptance of Reinsurance business is highly diverse and widely spread geographically and the Reinsurance Broker, by nature of his wide travel and continuous contact with the world market, is uniquely placed to match this supply of reinsurance cover with the demand that exists for it.

\section{BROKER'S ROLE FOR EQC}

This brief introduction paints the broader picture of the role of the Reinsurance broker. Moving now from the general to the specific; what is his role in dealing with the Earthquake risk here in New Zealand, and how does he set about meeting those challenges which must certainly be amongst the most exciting and daunting facing any Reinsurance Broker today? His objective is, as stated earlier, to work with his clients the New Zealand Earthquake \& War Damage commission to identify potential exposures, and to find realistic solutions. In broad terms this means covering as much as possible of the New Zealand Earthquake Risk outside New Zealand, at the best available rates, with properly solvent reinsurers, on technically appropriate conditions. Having achieved this objective he will maintain continuous Iiaison and dialogue with the EQC and will need to be alert and proactive in dealing with the many difficult matters which will demand attention during the currency of the Reinsurance. I will consider the various factors which together have to be taken into account in order to fulfill his role successfully.

\section{TYPES OF COVERAGE}

There are two basic types of Reinsurance Coverage for Earthquake risks:-

\section{(a) The Surplus Method}

Under such arrangement the reinsurer accepts a proportionate part of the original insurance in exchange for a proportionate part of the premium. In the event of loss, he pays a proportionate part of the loss. Surplus reinsurance, both under treaty arrangements and facultatively, plays an important part in spreading the earthquake risk on a world-wide basis.

(b) The excess of Loss Method

Here the protection relates to the loss incurred by the Reinsured irrespective of the size or number of original insurance policies he may have accepted. He will recover up to the cover limit in respect of each loss, retaining for his own account an agreed sum. The main programme of the EQC pays NZ\$1,000,000,000 on each loss after the $\mathrm{EQC}$ has retained NZ\$1,000,000,000 on each loss. The technicalities surrounding this apparently simple coverage are very complex but are not the subject of this paper.

In dealing with the N.Z. earthquake risk the broker will examine the potential of each Reinsurance method but for the protection of an account such as that of the EQC, only the 
Excess Loss method can produce the necessary cover at acceptable rates.

\section{INFORMATION REQUIREMENTS}

In order to assess the risk, Reinsurers will need information under the following broad headings:-

\section{(1) Technical Information}

a) Frequency of earthquakes.

b) Severity of earthquakes.

c) Details of Building Codes.

d) Details of Government regulations.

\section{(2) Underwriting information}

a) Premium income.

b) Retention.

c) Aggregates.

d) Probable maximum losses (PML).

e) Claims history.

I will not discuss the detailed information requirement, as this has been very capably dealt with by Dr. Bruno Porro in his paper.

For proper risk assessment the reinsurer clearly must have before him full relevant information. At the same time the broker's duty is to present the proposition in the best light in order to secure a competitive price for his client, avoiding information "overkill" which will be counterproductive to the efficient handling of the placement.Herein lies one of the broker's most difficult tasks. Latest case law in the U.K. appears to demand that the broker must insist that every reinsurance underwriter receives and scrutinizes all the information the broker has received from the Reinsured. We are indeed informed that it is no defence that an underwriter has advised that he does not wish to see information of a certain type, if it is subsequently found that such information could have been material to a "prudent underwriter" in assessing the risk.

In practice these apparent requirements are difficult to comply with, as placing of business becomes so time-consuming as to prevent its completion: the broker, in close collaboration with the reinsured, having full knowledge of the Reinsurers and their trust, must make a choice as to exactly what information is made available, exercising great care not to withhold information which could affect Reinsurers underwriting judgment. Any wider enquiry from Reinsurers will, of course, also be fully answered, if necessary after consultation with the client and a note to this effect is included in all our placing documents.

\section{THE MARKET PLACE}

Armed, therefore, with full information, and having decided on the correct and proper information to be disclosed, the broker is ready to enter the market place.

The market for Reinsurance has few geographical frontiers, and probably involves a freer international exchange than for any other type of international commerce. Vast liabilities are assumed, and vast flows of currency take place with minimal official interference; and with relatively uncomplicated (sometimes inadequate) documentation. Trust in each other between the market practitioners built over many years is the essential lubricant which allows this to happen, and without which a viable market would not exist.

The centre of the world Reinsurance market lies in London. The reason for London's predominance can be traced in part to London's importance over the last two centuries as a centre of world trade, with London Insurance Companies blazing a trail in the wake of the global activities of London merchants. It may also be explained in part by the presence of Lloyd's which for three centuries has been a centre of capital and insurance expertise and which together with a unique entrepreneurial structure and flair, has been the only consistent major supplier of Reinsurance service and capacity for catastrophe risks. Lloyd's with the London company market together make up the London Reinsurance market, and within the square-mile of the city this market is personified on a dayto-day basis by some 300 individual underwriters in the Non-marine branch alone. The role of the Broker is to get the best out of this extremely heterogeneous and unpredictable market place.

In addition to the huge capacity available within this London market place, there is a substantial further capacity waiting to be tapped in other parts of the world, and the broker must be able to access this capacity using the latest technology if he is to maximise the volume to be placed. A table (Appendix I) gives an indication of make-up of the Non-marine market place and its acceptance of the EQC programme.

In theory there is no reason why banks and other financial institutions should not be involved - in practice, however, this does not happen, partly for regulatory reasons, and partly because bankers find the way our business is handled to be alien and the rates of premium at which risk is transferred to be too low: the expertise of physical risk assessment is very different from the risk assessment techniques of bankers. Nevertheless the possibility of using such markets must always be kept under review.

We are often asked to estimate the world capacity of the various categories of Reinsurance and usually cannot give a clear-cut answer for there are a number of factors which influence capacity. 
FACTORS, WHICH INFLUENCE CAPACITY

a) Rate of premium

The more generous the rate for any business, the higher the capacity - not only will a higher rate attract new market onto a risk, but individual underwriters will accept higher liabilities if they believe the rate is good. Here the role of the broker is critical in judging on behalf of his client, the optimum balance of rate and capacity combining this with the ability to forecast what is achievable given the state of the market at that particular time. As the market capacity is filled, so rate increases produce diminishing returns in terms of additional capacity attracted and, as the increase will apply to the whole placement, will, beyond a critical point, not be justified by the additional capacity achieved.

\section{b) Cycles}

Reinsurance capacity will also be influenced by the phase of the market cycle. As with the sale and purchase of any product, periods of excess supply will succeed periods of excess demand: at present, for example, considerable new capital has been attracted into the market enabling larger lines to be placed at rates and conditions more favourable to the Reinsured. This factor may affect capacity by as much as $20 \%$ from the top of one cycle to the bottom of the next.

\section{c) Loss experience}

Another allied factor which will affect capacity is the frequency of earthquake losses over the preceding period. A high incidence of loss will lead to a withdrawal of capacity. There is a well established pattern of fair-weather friends who enter the market when they perceive a profit is to be made, only to withdraw as their fingers are burnt. Though the rating and acceptance of reinsurance business is an inexact science, a strong technical background, together with the ability to take a long-term view, is essential for successful underwriting: There is nevertheless a significant float of capital that washes in and out of the market according to profit perceptions, which in many instances lacks the proper management to make it a sound long-term part of the market.

\section{d) Balance}

Balance of premium to liability is a further factor affecting capacity. Catastrophe reinsurance is by its nature an unbalanced business with large exposures and modest premium flows.

In territories where an underwriter receives a high volume of premium he will be more disposed to offer high capacity; for example, the earthquake capacity offered by London underwriters to all U.S. insurance carriers will far exceed that offered to EQC and other N.Z. carriers. This is because the large volume of other business attracts further earthquake capacity into the market. In theory, of course, a worldwide market without geographical frontiers should imply equality of available capacity irrespective of territorial origins but earthquake reinsurance is but one aspect of a complex market place, and a balanced flow of premium spread across the sectors of Reinsurance business will increase available capacity.

\section{e) Previous commitments}

clearly a reinsurer must watch his overali commitments in any given earthquake zone with the greatest care and previous exposures accepted will limit additional capacity and the rate at which it is offered. Here in New Zealand many of the world's Reinsurers were already participating in covers for the private sector companies when we came to market the EQC business, and to the extent that these prior commitments were perceived as cumulative, they would have limited the placement achieved.

\section{f) Security}

Perhaps the most important role of the Reinsurance Broker when considering our market place is his ability to assess and advise upon the financial strength of Reinsurers with whom he will place the business. will the reinsurer still exist when the loss occurs and will he be willing and able to pay quickly? suffice it to say that this is an onerous, difficult and responsible task and one to which substantial resources are devoted in an attempt to weed out unsatisfactory carriers.

Standards applied to potential Reinsurers are of wide significance, because they concern not only the eventual recovery of losses, but also the capacity available, and rating levels for, as in many activities, cheap products are available of an inferior quality.

\section{FACTORS AFFECTING RATING LEVELS}

I would like to turn now to other factors which affect rating levels:-

\section{a) Risk information}

Clearly the factor which principally governs rates is the mix of technical elements relating to seismology of the territory, the vulnerability of insured interests, the insurance conditions, and information relating to the portfolio to be protected. Dr. Bruno porro has covered these factors in detail and I have summarized some aspects earlier in this paper.

I will concentrate on the market factors which affect rates. 
b) Capacity

As you will have realized the factors which affect premium rate are closely related to those affecting capacity and the level of capacity itself required usually will affect the rate of premium. A very large programme will command a higher relative rate than a more modest cover.

\section{c) Market Cycle}

The phase of the market cycle will affect rates as it does capacity.

\section{d) Previous Commitments}

In a zone where he is not previously committed a reinsurer will accept earthquake exposure at rates well below those at which he can be tempted to participate if he is already heavily committed. Being a trader in Reinsurance capacity, he will always keep capacity up his sleeve for the really tempting offer.

\section{e) Balance}

The volume of supporting business will influence rates. In an area such as N.Z. rating levels may, in theory, be somewhat higher as underwriters receive relatively ittle other business.

\section{f) Loss Incidence}

Recent incidence of loss too will affect rates, and losses from any part of the world will have some effect on worldwide rating levels. By the nature of earthquake business consisting of a relatively small pool of premiums and high liabilities, underwriters will consider the pool as a whole. After a major loss Reinsurers will have the need to earn a "pay back"premium to replenish the world-wide earthquake fund. All those reinsured by this pool will gain or lose from this fact depending upon whether theirs was the most recent loss, though it would be true that the heaviest impact as regards increased rate would normally apply to that institution most recently affected. In a perfect world individual losses should have no impact on day-to-day rating; our world is far from perfect, however, and the reinsurance market has a powerful commercial orientation which often defies rational or technical truths.

As will be clear from what I have written, the rating of Catastrophe protections is a very inexact science; the final rate achieved will reflect the current market view of the relative importance attached to each of the elements I have mentioned. The fact that we operate in a truly commercial international market place ensures that there is never any certainty in what can be achieved either in terms of capacity or rates. Hence our reluctance to forecast; hence too the continuous excitement and challenge of our task.

\section{MARKETING}

There are many complex factors surrounding the marketing of a major earthquake programme and I will touch only on two.

\section{a) Selection of leader(s)}

The reinsurance market works broadly on a system of "leading Reinsurers" and "followers" and the choice of leader(s) is crucial to the proper rating and completion of all types of Reinsurance business. This is particularly true of a major earthquake catastrophe programme.

The leader has, on the one hand, to have the confidence of the broker and his client that he is technically capable and will quote a fair rate, and on the other to have the confidence of his following market, so that the broker may expect support for his quotation when he seeks to complete the cover. To ensure completion, a major cover must have a recognized lead in the London Market usually in Lloyd's, will have to be supported by significant leaders in the London Company market and will need the further support of the leading companies outside London.

In the end it is this consensus of major leaders, normally negotiated on a face to face basis, which will pave the way for completion of the cover: this may take a number of weeks, while every reinsurance carrier, the world over, each of whom will have been carefully evaluated on security and other grounds, is approached either personally or electronically. In the case of our N.z. Earthquake cover, no less than 538 reinsurers were approached, of which 439 accepted shares of the business.

\section{b) Layering}

In general it is not possible to achieve optimum capacity without breaking the coverage into layers which pay successively dependent upon the size of loss.

Individual underwriters take very different views of level, type, at any one time and by layering a large programme it is possible to cater for their differing appetites and to extract maximum capacity.

By careful structuring of the programme layers can, for example, be produced which have high past loss frequency carrying a high rate, immediately succeeded by a higher layer free of past losses which will be perceived as less exposed and thus more keenly rated. Underwriters seeking either type of cover will thus be accommodated. Underwriters appetites differ in many other ways which may similarly be accommodated by appropriate layering.

Different leaders will be approached at the various levels, and the final rate 
quoted will be a compendium of the best rates for each layer at which the broker believes he can complete the coverage.

The technique of layering is infinitely variable and holds the key to proper utilisation of the market and demands of the broker an intimate knowledge both of the business and the market if it is to be successfully applied.

\section{CLAIMS}

Important as is the placing of a Reinsurance cover, the final judgment of a brokers performance depends on his ability to collect claims rapidly when they occur.

The logistics of rapid collection from 500 reinsurers is daunting and having had experience of considerable numbers of catastrophe collection most Reinsurance Brokers are extremely conscious of the resources and determination required to collect and pass on the huge sums which may be involved.Brokers will have produced programmes, backed by electronic systems, to speed the payments, and to chase every Reinsurer who does not conform with their timetable.
It is difficult to forecast other services which may be demanded of a Broker at the time of catastrophic loss. They will involve collaboration with reinsurers in the assessment or control of loss and the appointment of loss assessors.They may involve working with Exchange control and Tax authorities for the loss collection may involve very large currency movements both nationally and across international frontiers. These may affect exchange rates, share prices and property values, and Government authorities may require the Brokers collaboration to monitor and control these movements.

The first requirement will, however, remain the fast and smooth flow of loss payments.

\section{CONCLUSION}

The role of the Reinsurance Broker is varied and responsible. It is also a source of satisfaction as he is providing a service which assists not only Institutions such as EQC, but also whole communities, to go about their daily lives with perhaps more peace of mind than would otherwise be possible.

APPENDIX I

GLOBAL E.Q.C. PLACEMENT PATTERN

\begin{tabular}{|c|c|c|c|c|c|c|}
\hline & $\begin{array}{c}\text { NO. } \\
\text { APPROACHED }\end{array}$ & $\begin{array}{l}\text { NO. } \\
\text { ACCEPTED }\end{array}$ & $\begin{array}{l}\text { No. } \\
\text { DECLINED }\end{array}$ & z & $\begin{array}{l}\text { ACCEPTANCE } \\
\text { NZ\$ }\end{array}$ & \& \\
\hline LLOYD'S (INC. INTERMARKET) & 234 & 223 & 11 & 4.70 & $294,410,000$ & 29.441 \\
\hline LONDON COMPANY MARKET & 85 & 81 & 4 & 4.71 & $264,000,000$ & $\underline{26.400}$ \\
\hline SUB TOTAL & 319 & 304 & 15 & 4.70 & $558,410,000$ & 55.841 \\
\hline EUROPEAN MARKET & 99 & 67 & 32 & 32.32 & $211,200,000$ & 21.120 \\
\hline NORTH AMERICAN MARKET & 57 & 67 & 32 & 66.67 & $52,720,000$ & 5.272 \\
\hline $\begin{array}{c}\text { LOCAL MARKET NZ \& } \\
\text { AUSTRALIA }\end{array}$ & 27 & 24 & 3 & 11.11 & $139,470,000$ & 13.947 \\
\hline OTHER MARKETS & 36 & 25 & 11 & 30.56 & $38,200,000$ & 3.820 \\
\hline TOTAL & 538 & 439 & 99 & 18.40 & $1,000,000,000$ & 100.000 \\
\hline
\end{tabular}

